\title{
The Approach to Carbon Emission Quotas of Road Transportation: A Carbon Emission Intensity Perspective
}

\author{
Xiao Li $\mathbb{D},^{1,2}$ Li Gao $\mathbb{D}^{1},{ }^{1}$ and Jintao Liu $\mathbb{D}^{3}$ \\ ${ }^{1}$ School of Mechanical Engineering, Beijing Institute of Technology, Beijing 100081, China \\ ${ }^{2}$ Research Institute of Highway Ministry of Transport, Beijing 100088, China \\ ${ }^{3}$ National Research Center of Railway Safety Assessment, Beijing Jiaotong University, Beijing 100044, China
}

Correspondence should be addressed to Li Gao; ligaobit@bit.edu.cn

Received 3 July 2020; Revised 29 November 2020; Accepted 11 December 2020; Published 23 December 2020

Academic Editor: Mehdi Nourinejad

Copyright (c) 2020 Xiao Li et al. This is an open access article distributed under the Creative Commons Attribution License, which permits unrestricted use, distribution, and reproduction in any medium, provided the original work is properly cited.

\begin{abstract}
Carbon trading is an effective measure for the road transportation to reduce energy consumption and carbon emissions. Carbon emission quotas are the primary concern to ensuring the efficiency of carbon trading. However, the existing studies have mostly focused on carbon emission quotas in different regions, i.e., countries and provinces. Few literature studies simulate carbon quota allocation in the road transportation. A novel approach from the perspective of carbon emission intensity of vehicle is proposed, on the basis of data envelopment analysis (DEA) model. Unlike other studies, the idea of allocation of baseline excitation is introduced and the intensity is included in the model as the baseline. Firstly, the Delphi method is employed to select input and output indicators. Secondly, carbon emission intensity is determined by the cumulative distribution function (CDF). Furthermore, the carbon emission quotas in road transportation in 30 provinces of China are used to validate the model. The results show that (1) the carbon emission intensity of commercial trucks and buses in China's road transport industry is $75.04 \mathrm{~g} / \mathrm{t} \cdot \mathrm{km}$ and $13.12 \mathrm{~g} / \mathrm{p} \cdot \mathrm{km}$, respectively; (2) the provinces of Shanghai, Guangdong, and Xinjiang have the greatest carbon reduction potential and Henan, Hunan, and Anhui have the largest increase in emission quotas; (3) compared with traditional "history responsibility" and "baseline" methods, the proposed approach increases allocation efficiency by $19 \%$ and $14 \%$, respectively; and (4) the approach can make the carbon emission quotas play the role of incentive while taking fairness into account and can more effectively promote the implementation of carbon trading system in road transportation.
\end{abstract}

\section{Introduction}

China has become the largest carbon emission country in the world and promised to reduce the intensity of carbon dioxide emissions per unit of GDP in 2020 by $40 \%$ to $45 \%$ from 2005 and to reach peak carbon emissions in $2030[1,2]$. However, China is facing pressures in the international negotiation on $\mathrm{CO}_{2}$ emission control and climate change mitigation, in terms of the following aspects, including the growing emphasis on international environmental issues from the public and the government, the increasing demand for energy and resources in the development of economics, and the fact that a perfect carbon reduction mechanism has not been well established $[3,4]$. Carbon trading is an important means for China to achieve the goal of carbon emission reduction, and its fundamental idea is to use market means to regulate carbon emissions. China issued the Plan for the Construction of the National Carbon Emissions Trading Market (Power Generation Industry) in 2017, marking the official launch of the national carbon trading market in China.

As an industry with the highest oil consumption and the most rapid growth in energy demand and carbon emissions, transportation is in need of improved energy efficiency and low-carbon development. In 2018, the road transportation recorded a total operating passenger volume of 13.672 billion persons and a total operating freight volume of 39.569 billion tons, accounting for $76 \%$ and $78 \%$ [5], respectively, of the total transport volume, as shown in Figure 1. The road transportation is the main component of transportation and 


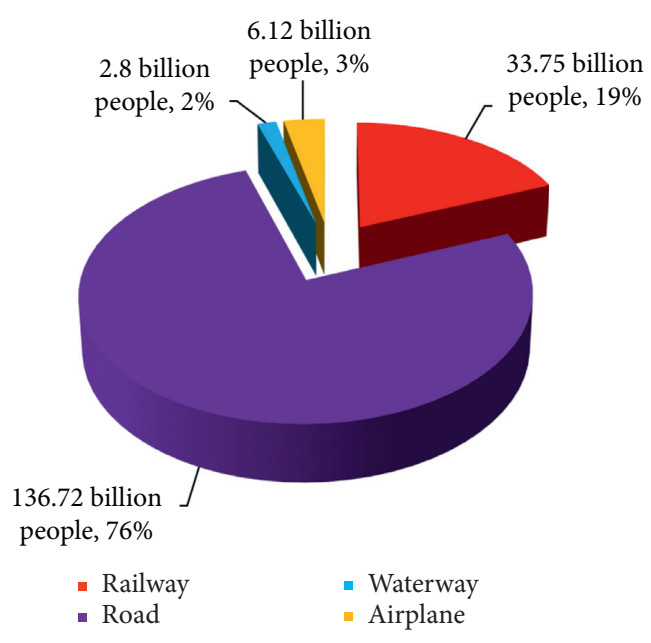

(a)

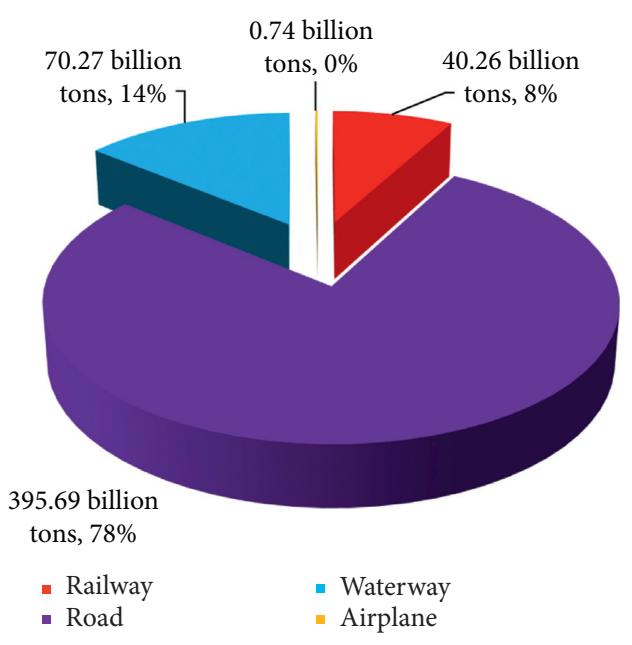

(b)

Figure 1: The proportion of road transportation. (a) The proportion of road passenger traffic. (b) The proportion of road freight volume.

the key area of energy consumption and carbon emissions. In order to realize the carbon reduction commitment, how to establish the carbon trading mechanism to measure and manage road transport emissions has become an urgent issue to be solved. Here, a scientific allocation of the emission quotas is essential for establishing the carbon trading mechanism of the road transportation.

Carbon emission quotas directly determine the operational efficiency of the carbon trading market, which has attracted wide attention from scholars all over the world [6-8]. The carbon emission quota allocation is a kind of special resource allocation process in which reasonable methods are applied to allocate the total quotas across the provinces.

In terms of study directions, there are two main directions including the fairness principle-based research and the efficiency principle-based research. In the fairness principle-based research, some classic models are widely used, such as the "historical responsibility" model and the "baseline" model. In other research studies, the models targeted to distribution efficiency are studied, i.e., the DEA(data envelopment analysis-) related models. The fairness principle will probably affect distributive efficiency and incentives. And the efficiency principle will probably affect the fairness, which might cause implementation difficulty and fierce resistance from companies. There are few studies that can combine the efficiency, the fairness, and the incentives.

In terms of application industries, there are some differences between the road transportation and the other industries. Vehicles are the main source of energy consumption and carbon emissions. Carbon emission by mobile point sources, as in the road transportation, is more difficult to monitor than emission by fixed-point source, as in the electricity and steel industries. The road transportation has certain difficulties in the scientific allocation of initial quotas. The first is the collection of carbon emission data of enterprises. The second is the selection of the indicators for the road transport industry which affect the allocation of initial allowances for carbon emission. The third is the demarcation about the baseline of vehicle carbon emission intensity for the road transport industry. At present, few scholars have conducted research on the road transportation.

According to the above, it is urgent and necessary to put forward a quota allocation model which can combine the fairness, the efficiency, and the incentive, conforming to the features of road transportation industry. Carbon emission intensity of vehicle is an important characteristic index of mobile source emission, which can effectively represent the carbon reduction potential and incentive effects. For this reason, we carry out the research on the approach for carbon emission quotas of road transportation from a carbon emission intensity perspective.

In this article, the DEA is utilized to address the carbon emission quota allocation problem in the Chinese road transportation. The DEA methodology can handle desirable and undesirable outputs simultaneously, which is highly fitted with the circumstance of carbon emission quota allocation problem. However, due to the point of the DEA that is put on the efficiency, the fairness and the incentive may be ignored. To solve this problem, we introduce the baseline of vehicle emission intensity into the DEA framework. To this end, firstly, we establish a comprehensive BL-DEA (baseline DEA) model by theoretical analysis. Secondly, the Delphi method is employed to select input and output indicators. Thirdly, carbon emission intensity is determined by the cumulative distribution function (CDF). Finally, the carbon emission quotas in the road transportation in 30 provinces of China are used to validate the model.

Our research is expected to be helpful for the more scientific allocation of road transportation carbon emission quotas to the provinces of China and promote the development of the carbon trading market in China.

The rest of this paper is organized as follows: Section 2 reviews relevant literature. Section 3 introduces the carbon emission quota model, the selection method of indicators, 
and the cumulative distribution function of emission intensity. Section 4 carries out data analysis and simulation calculation. Finally, Section 5 contains the conclusions and shortcomings of this study which provides guidance for further work.

\section{Literature Review}

This article focuses on the approach for the carbon emission quota allocation problem in the road transportation. In the carbon emission quota allocation, there are mainly two relevant research directions, including the fairness principlebased methods, such as the "historical responsibility" model and the "baseline" model, and the efficiency principle-based methods, i.e., the DEA-related models.

\subsection{Fairness Principle-Based Quota Allocation Methods.} According to the fairness principle, carbon emission quotas could be allocated in proportion to the historical emissions, the population, the emission intensity, and so forth. In 1986, the American economist Dales first proposed the concept of carbon trading [2] and pointed out that the world needs to establish a pollutant emission system. Under such system, each country will have the corresponding emissions and be issued with the emission permit so that it can trade the emissions like commodities. Carbon trading is designed to reduce carbon emissions. Therefore, the primary criterion for evaluating the carbon trading mechanism is environmental effectiveness, i.e., the level of carbon emission reduction [9]. The total amount of initial allowance allocation largely determines the level of carbon emission reduction. Dales employed different models to evaluate the level of carbon emission reduction in the EU, finding out that the excessively loose total amount of initial allowances is the most major factor affecting carbon emission reduction $[6,7]$. Boehringer et al. [8] also calculated the total amount of carbon allowances, and the results showed that the excessively loose carbon allowances will have a serious negative external impact on carbon emission reductions. Therefore, the issue of initial allowance allocation has become the first issue to be resolved in the carbon trading mechanism.

In order to address the issue of the allocation of initial allowances for carbon emission, Westing [10] suggested that the area of land could be used as a measure for allocating emissions. Jensen and other scholars proposed a historical emission-based allocation model [11], i.e., the historical responsibility allocation model combining the historical responsibility for $\mathrm{CO}_{2}$ emissions in various regions with the policy objective of allocating future emissions. Grubb [12] proposed a modified model of average distribution based on the population, under which everyone should have equal rights and be allocated with equal emission allowances. Kverndokk [13] also advocated the allocation of carbon emissions by the population size of the social subject participants. Yi et al. [14] believed that the principle of sustainable development is of great significance to constructing a common but different scheme for regional allocation of carbon allowances. Yu et al. [15] proposed another concept of cumulative per capita emission, advocating the idea of equal or convergent cumulative per capita emission over a period of time. However, the above models are humancentered and ignore the fact it is governments that are responsible for carbon emissions, leading to deviations in allocation targets. The baseline method was thus proposed to solve the problems. Under the baseline method, allowances are allocated based on the standard emission rate for an industry, i.e., enterprises with better emission reduction performance gain more benefits through allowance allocation. Gagelmann [16] studied the impact of historical responsibility and baseline method on the liquidity of the carbon trading system, carbon price fluctuations, and corporate investment. It was found that compared with the "historical responsibility," the "baseline method" can better stimulate the liquidity of the emission trading system and affect the future development of the carbon trading system through the expected effect of enterprises.

The allocation of initial allowances for carbon emission is a complex system issue that involves multiple aspects. Therefore, many integrated allocation models and allocation schemes have gradually matured. For example, Filar and Gaertner [17] used nonlinear programming and Shapley values to apportion worldwide carbon emission reduction responsibilities. Eyckmans and Tulkens [18] adopted a cooperative game approach to discuss the issue of the sharing of emission reduction responsibilities among different countries. Viguier et al. [19] employed a two-level computable general equilibrium model to study the allocation of emission allowances among EU member states. Phylipsen et al. [20] proposed a trinity partial method to distribute emission reduction burdens among EU member states. Groenenberg et al. [21] expanded the trinity partial method to the whole world. Den Elzen et al. [22, 23] further proposed a multiphase commitment method that allows delayed participation of developing countries. Other scholars such as Bohringer et al. [24] and Ekholm et al. [25] proposed that the selection of emission reduction indicators should emphasize the anthropogenic reduction of $\mathrm{CO}_{2}$ emissions and the fair allocation among countries. Through such two factors, the total amount of $\mathrm{CO}_{2}$ emission reduction could be derived. Baer [26] also used the product of GDP per capita and cumulative emissions per capita as a fairness indicator in the GDR scheme. BJ-Tang et al. [27] proposed a reasonable and effective allocation scheme for the government with traditional methods from the industry perspective. The results showed that the quotas of the grandfathering scheme are larger than those of the benchmarking scheme. Rong Han et al. [28] examined the allocation of carbon quotas in the Chinese road transportation and forested the vehicle possession using a gray forecast model and trend extrapolation. The finding was that both the vehicle possession in the road transportation and the corresponding carbon emission present the trend of growth.

There are some limitations about the fairness principlebased quota allocation methods. For instance, under the "historical responsibility" allocation model, it is difficult to accurately calculate the due allowances for newcomers in the market. Furthermore, there would be such a phenomenon 
that enterprises with many carbon emissions are allocated with many allowances, while those making technical improvements to reduce carbon emissions are allocated with few allowances. This would possibly lead to incentive distortions.

The "baseline method" has strong industry characteristics and can accurately match an industry's regulatory needs, giving effective play to the subjective initiative of enterprises' independent emission reduction. However, the reasonable selection of the industry baseline is supported by a large amount of actual industry data that are usually difficult to collect.

\subsection{Efficiency Principle-Based Quota Allocation Methods.} The quota allocation methods based on the fairness principle will probably affect distributive efficiency. The efficiency is an essential factor of a practical quotas allocation method. Hence, some scholars conducted research on the allocation methods based on the efficiency principle. The research of Wang pointed out that the allocation of initial allowances for carbon emission can be considered as a cost allocation problem under total control [4]. Therefore, a data envelopment analysis (DEA) based on operations research can be used to establish an allowance allocation model under which several input/output parameters are set as constraints to solve the allowance allocation problem. Cook and Kress [29] put forward a model under the DEA framework to deal with the fixed input allocation problem. Given the limited total allowances, Lozano and Villa [30] and Lozano et al. [31] also studied such problems as the allocation of emission permits. Lins et al. [32] introduced the idea of zero-sum game to solve the problem that decision units in the DEA model were independent from each other and proposed an improved ZSG-DEA model. Lin and Ning [33] used the ZSG-DEA model to study the efficiency of allowance allocation among European countries in 2009. Pang et al. [34] studied, basing on the ZSG-DEA model, how to maximize the efficiency of allowance allocation among countries. Feng et al. [35] employed the centralized allocation model based on improved DEA to study the allowance allocation among OECD countries under the hypothesis of constant scale returns and variable scale returns. Chiu et al. [36] adopted the ZSG-DEA model of superrelaxed basis measurement to study the initial allowance allocation among EU countries, clarifying how to maximize the allocation efficiency. When using the DEA model to solve the problem of allocation of trading allowances for carbon emission, it is important to deal with the undesirable output of carbon emissions. Chung et al. [37] and Zhou et al. [38] employed the directional distance function to obtain the optimal solution of DEA by increasing necessary output and reducing unnecessary output. Seiford and Zhu [39] adopted the method of converting unnecessary output into ideal mathematical output under the condition of classification invariance. Reinhard et al. [40] and Zhang et al. [41] chose to treat unwelcome outputs as input, and Sueyoshi et al. [42, 43] proposed the usage scale adjustment measures to deal with undesired and expected results in a unified manner.
2.3. Contribution of This Paper. From the above review, it can be seen that scholars have conducted a great deal of research on the allocation of emission quotas. But the following problems remain. Firstly, current research has focused more on national or provincial allocation, while few scholars carried out research on the road transportation. Although Han et al. [28] analyzed the carbon emission quotas in the Chinese road transport sector from the perspective of carbon trading and designed a carbon trading mechanism, the research focused more on the calculation of the total amount of carbon quotas under different policy scenarios and on the macro policies. Secondly, the existing DEA model fails to consider the performance incentives for emission reduction based on the emission intensity and thus is not conducive to improving the efficiency in emission reduction in industry development.

On this basis, this paper analyzes the carbon emission quotas in the Chinese road transportation from the perspective of emission intensity and pays more attention to the allocation between the provinces. The research introduces the vehicle emission intensity as the baseline to establish an improved BL-DEA model, with the following contribution.

Firstly, we propose an approach for the carbon emission quotas of the road transportation, which takes the fairness, the efficiency, and the incentive among all participators into account. Specifically, the consideration of the fairness makes the generated allocation mechanism easier to accept. The introduction of baseline theory has brought about a significant incentive effect. Meanwhile, the application of DEA ensures the distributive efficiency.

Secondly, through the statistical analysis of the vehicle data, we identify the baseline of carbon emission intensity by the use of the cumulative distribution function. This solves the problem that the baseline of road transportation is hard to determine, which can provide a reference for the carbon emission level assessment.

Thirdly, the proposed approach is applied to the empirical study of the quotas of allocation in the road transportation to 30 provinces of China.

To conclude, this paper presents a feasible way for the Chinese government to achieve the carbon emission reduction target. In theories, this article develops a new approach to address the carbon emission quotas allocation problem. In practice, it solves a real-world problem by providing practical findings and implications.

\section{Methodology}

3.1. BL-DEA Model. The premise of carbon trading for road transport is the benign development of the industry cannot be affected. Therefore, the allocation of initial quotas must reflect efficiency and fairness. The ultimate goal of reducing the carbon emission requires incentives to be present. The BL-DEA model is established based on the following principles:

(1) Prioritize the development of the industry, i.e., the initial allowance allocation must maximize the overall efficiency 
(2) Under the initial allowance allocation plan of each enterprise, the total allowance must be fully allocated

(3) Reflect the idea of performance incentive, i.e., initial quotas allocation must be combined with the baseline of emission intensity

Beasley [44] pointed out in his research that in order to maximize the overall efficiency of the allocation objects, decision-makers can use the average efficiency optimization instead of the single DMU (diesel multiple-unit) efficiency in the traditional DEA model.

Assume that there are a total of $n \operatorname{DMU}_{q}(q=1,2, \ldots, n)$ of the same type, each of which has $m$ types of output and $p$ types of input. We use $y_{r q}$ to represent no. $r(r=1,2, \ldots, m)$ output of $\mathrm{DMU}_{q}$ and use $x_{i q}$ to represent no. $i(i=1,2, \ldots, p)$ input of $\mathrm{DMU}_{q} ; u_{r}$ represents the weight coefficient corresponding to no. $r$ output, and $v_{i}$ represents the weight coefficient corresponding to no. $i$ input; $e_{q}$ represents the efficiency of $\mathrm{DMU}_{q}$. We take the initial allowance for carbon emission of $\mathrm{DMU}_{q}$ as a special input, represented with $f_{q}$. We use $F$ to represent the total amount of allowances to be allocated. According to Beasley's research, we use the average efficiency maximization as the objective function and can get the following model:

$$
\begin{aligned}
& E=\max \frac{1}{n} \sum_{q=1}^{n} e_{q} \\
& \quad \frac{\sum_{r=1}^{m} u_{r} y_{r q}}{f_{q}+\sum_{i=1}^{p} v_{i} x_{i q}}=e_{q} \\
& \quad 0 \leq e_{q} \leq 1, q=1,2, \ldots, n \\
& \text { s.t. } \\
& \quad u_{r} \geq 0, v_{i} \geq 0, r=1,2, \ldots, m, i=1,2, \ldots, p \\
& \sum_{q=1}^{n} f_{q}=F .
\end{aligned}
$$

In model (1), $E$ is the objective function, which maximizes the average efficiency; the first constraint describes the calculation method of $e_{q}$; the second and third constraints describe the value range of $e_{q} u_{r}$ and $v_{i}$, and the last constraint describes the total amount of allowances that have been allocated.

We assume that the optimal solution of the objective function is $E^{*}$, and it is easy to prove that the result of model (1) is (weak) valid for DEA, that is, the solution $E^{*}=1$ exists, which is proven as follows.
Assume

$$
\begin{array}{r}
\bar{U}=\left(u_{1}, u_{2}, \ldots, u_{m-1}\right)=(0,0, \ldots, 0), \\
u_{m}=\frac{F}{\sum_{q=1}^{n} y_{m q}}, \\
f_{q}=\frac{y_{m q} F}{\sum_{q=1}^{n} y_{m q}}, \\
\bar{V}=\left(v_{1}, v_{2}, \ldots, v_{p}\right)=(0,0, \ldots, 0), \\
\because e_{q}=\frac{\sum_{r=1}^{m} u_{r} y_{r q}}{f_{q}+\sum_{i=1}^{p} v_{i} x_{i q}}=\frac{u_{m} y_{m q}}{f_{q}}=\frac{F y_{m q} / \sum_{q=1}^{n} y_{m q}}{F y_{m q} / \sum_{q=1}^{n} y_{m q}}=1, \\
\therefore E *=\frac{1}{n} \sum_{q=1}^{n} e_{q}=1 .
\end{array}
$$

In order to obtain a scientific allocation method for $f_{q}$, we take the optimal solution $E *=(1 / n) \sum_{q=1}^{n} e_{q}=1$ of model (1) as a new constraint and the maximum and minimum values of $f_{q}$ as objective functions, to establish model (3), and can obtain the variation range of $f_{q}$ :

$$
\begin{aligned}
& \frac{\max }{\min } f_{q} \\
& \frac{\sum_{r=1}^{m} u_{r} y_{r q}}{f_{q}+\sum_{i=1}^{p} v_{i} x_{i q}}=e_{q} \\
& 0 \leq e_{q} \leq 1, q=1,2, \ldots \\
& u_{r} \geq 0, v_{i} \geq 0, r=1,2 \\
& \text { s.t. } \\
& \sum_{q=1}^{n} f_{q}=F \\
& \frac{1}{n} \sum_{q=1}^{n} e_{q}=1 .
\end{aligned}
$$$$
0 \leq e_{q} \leq 1, q=1,2, \ldots, n
$$$$
u_{r} \geq 0, v_{i} \geq 0, r=1,2, \ldots, m, i=1,2, \ldots, p
$$

In model (3), $\max f_{q}$ and $\min f_{q}$ are used as objective functions to calculate the maximum and minimum optimal solutions, respectively. The last constraint guarantees that the value of $f_{q}$ meets the requirement of optimal efficiency. The other constraints are the same as model (1).

We record the minimum optimal solution obtained by model (3) as $S_{q}$ and the maximum optimal solution as $L_{q}$. In general, $S_{q}<f_{q}<L_{q}$, If $S_{q}=f_{q}=L_{q}$ exists in DMU, and it 
means that the allocation result of the DMU has been determined.

In order to reflect the incentive effect of carbon emission intensity of vehicle in the model, we need to consider combining the DEA model with the baseline of emission intensity. We make the value of $f_{q}$ close to the value allocated under the baseline of intensity, as much as possible. $f_{q 0}$ is represented as the initial quota value allocated under the baseline method. Based on the above, we can get the following model:

$$
\begin{aligned}
& \min \sum_{q=1}^{n}\left|f_{q}-f_{q 0}\right| \\
& \quad \frac{\sum_{r=1}^{m} u_{r} y_{r q}}{f_{q}+\sum_{i=1}^{p} v_{i} x_{i q}}=e_{q} \\
& 0 \leq e_{q} \leq 1, q=1,2, \ldots, n \\
& u_{r} \geq 0, v_{i} \geq 0, r=1,2, \ldots, m, i=1,2, \ldots, p \\
& \text { s.t. } \sum_{q=1}^{n} f_{q}=F \\
& \frac{1}{n} \sum_{q=1}^{n} e_{q}=1 \\
& S_{q} \leq f_{q} \leq L_{q} .
\end{aligned}
$$

In model (4), the objective function is meant to get $f_{q}$ as close as possible to the $f_{q o}$. The last constraint guarantees that the value of $f_{q}$ lies between the maximum and the minimum optimal solution. The other constraints are the same as model (3).

Model (4) is a nonlinear programming whose objective function contains absolute value. It is hard to solve. To make it easier to solve, two intermediate variables $\alpha_{q}$ and $\beta_{q}$ are defined, where $\quad \alpha_{q}=\left(\left|f_{q}-f_{q 0}\right|+f_{q}-f_{q 0}\right) / 2$ and $\beta_{q}=\left(\left|f_{q}-f_{q 0}\right|-f_{q}+f_{q 0}\right) / 2$. It is easy to calculate that $\left|f_{q}-f_{q 0}\right|=\alpha_{q}+\beta_{q}$ and $f_{q}=\alpha_{q}-\beta_{q}+f_{q 0}$. After substituting them into model (4), we can get the equivalent model (5).

In model (5), the objective function of model (4) is converted to a linear function. $f_{q}$ in constraint is replaced by $\alpha_{q}-\beta_{q}+f_{q 0}$. The others are the same as model (4).

By solving model (5), we can get $\alpha_{q}$ and $\beta_{q}$ meeting the requirements of the objective function; therefore, $f_{q}=\alpha_{q}-\beta_{q}+f_{q 0}$. At this point, we complete the establishment of the BL-DEA model for carbon trading allowance allocation with the baseline idea introduced:

$$
\begin{aligned}
& \min \sum_{q=1}^{n} \alpha_{q}+\beta_{q} \\
& \frac{\sum_{r=1}^{m} u_{r} y_{r q}}{\alpha_{q}-\beta_{q}+f_{q 0}+\sum_{i=1}^{p} v_{i} x_{i q}}=e_{q} \\
& 0 \leq e_{q} \leq 1, q=1,2, \ldots, n \\
& u_{r} \geq 0, v_{i} \geq 0, r=1,2, \ldots, m, i=1,2, \ldots, p, \\
& \text { s.t. } \sum_{q=1}^{n}\left(\alpha_{q}-\beta_{q}+f_{q 0}\right)=F \\
& \frac{1}{n} \sum_{q=1}^{n} e_{q}=1 \\
& \quad S_{q} \leq \alpha_{q}-\beta_{q}+f_{q 0} \leq L_{q} .
\end{aligned}
$$

3.2. Selection of Indicators. There are many factors that affect the carbon emissions in the road transportation. To ensure the scientific and reasonable selection of indicators, this paper employed Delphi method for survey of experts in the transport industry. Delphi method, as a method for anonymous correspondence to feedback, is widely used in evaluation, forecasting, and determination of influencing factors. Some scholars also used it as a practical tool for statistical work $[45,46]$. Delphi method was used to conduct two rounds of expert consultation to determine the final input-output indicators.

Before the first round of survey, a preliminary indicator set was established through theoretical analysis, including 2 primary indicators and 10 secondary indicators, as shown in Figure 2.

The full mark frequency, grade sum, and coefficient of variation are selected as the basis for indicator screening, which means

(1) Full mark frequency $\left(P_{i}\right)$ : this indicator represents the ratio of the number of experts who are more than general important to the total number of experts. When $P_{i} \leq 50 \%$, it is deemed that the level of importance of the indicator is insufficient and the indicator will be deleted.

(2) Grade sum $\left(F_{i}\right)$ : it is the total score of expert evaluation of an indicator. This paper assigns 0,1 , and 2 to unimportant, general, and important in the first round of expert evaluation. When $F_{i} \leq n$, the indicator 


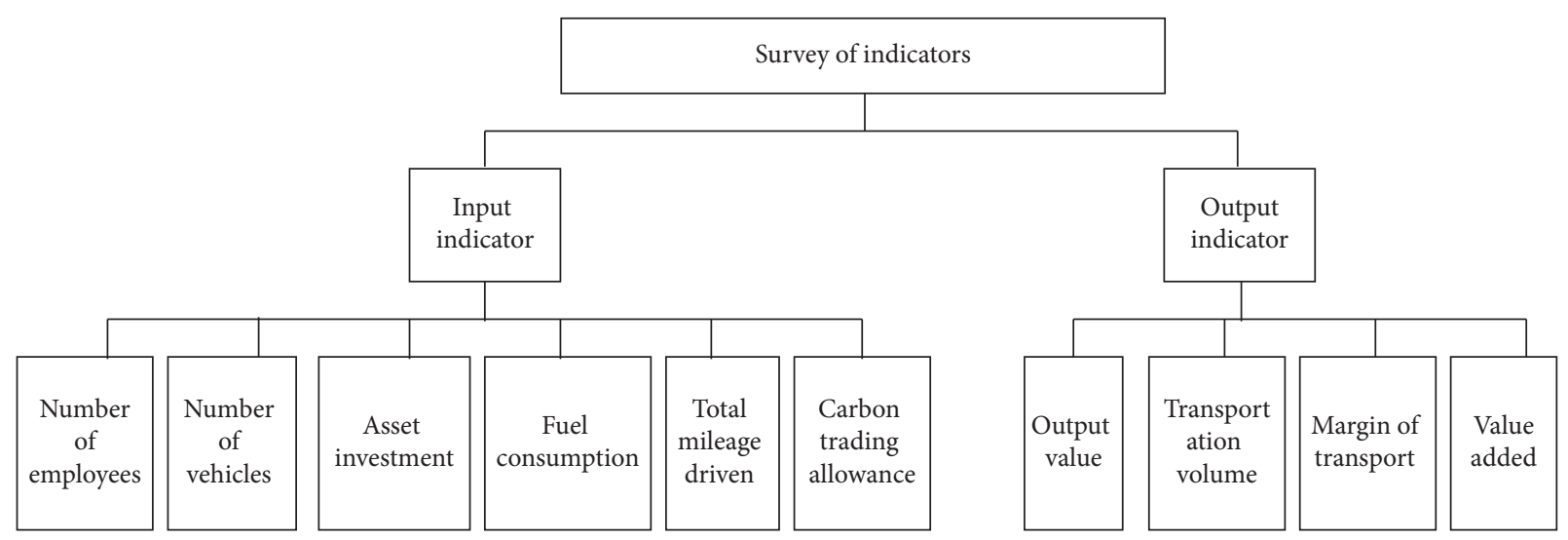

FIgure 2: Preliminary indicator set under Delphi method.

will be deleted; in the second round of expert evaluation, unimportant, less important, general, relatively important, and important are assigned 0, 1, 2, 3, and 4, respectively. When $F_{i} \leq 2 n$, the indicator will be deleted.

$$
F_{i}=\sum_{j=1}^{n} R_{i j}
$$

In the above formula, $F_{i}$ is the grade sum of the no. $i$ indicator; $R_{i j}$ is the value of the no. $j$ expert's score on the no. $i$ indicator.

(3) Coefficient of variation $\left(\mathrm{CV}_{i}\right)$ : it is used to judge whether experts have large differences in the evaluation of indicators. The coefficient of variation $(\mathrm{CV})$ is used for testing. The smaller the value is, the smaller the difference is:

$$
\mathrm{CV}_{i}=\frac{\sigma_{i}}{M_{i}}
$$

where $\mathrm{CV}_{i}$ is the coefficient of variation of the no. $i$ indicator; $\sigma_{i}$ is the standard deviation of the expert score of the no. $i$ indicator; $M_{i}$ is the arithmetic average of the expert score of the no. $i$ indicator.

In the first round of expert surveys, 50 questionnaires were distributed and 42 were recovered, with a recovery rate of $84 \%$ and an effective rate of $100 \%$. In the second round of expert surveys, 50 questionnaires were distributed and 40 were recovered, with a recovery rate of $80 \%$ and an effective rate of $100 \%$. Information of the two rounds of survey is shown in Table 1.

It can be seen from Table 1 that after the first round of survey, 4 indicators were deleted based on the full mark frequency and grade sum. In the second round of survey, each full mark frequency is greater than $50 \%$, each grade sum is greater than 80 , and each coefficient of variation is less than 0.2 . It can be considered that after this round of survey, the expert opinions have tended to be unified, and the indicator system can be determined.
To sum up, the number of employees, the number of vehicles, the fuel consumption, and the initial allowances for carbon emission are selected as input indicators under the BL-DEA model. The output value and transportation volume are selected as output indicators.

3.3. Emission Intensity Based on CDF. There are two main factors that affect the delimitation of the baseline value of carbon intensity in the road transportation. The first is that the selection of a reference indicator can accurately reflect the industry's performance gap in energy conservation and carbon reduction. The second is to confirm the specific situation of the current carbon intensity in the entire industry. In terms of indicator selection, compared with per unit mileage carbon intensity, per unit of passenger and freight turnover can both effectively reflect the carbon intensity of a vehicle and the carbon intensity of a passenger and freight vehicle in transport capacity, which complies with industry characteristics and is in line with existing statistical indicators of the road transport industry. The calculation formula of such indicator is as follows:

$$
c=\frac{m_{f} \rho Q_{l} k}{100000 W}
$$

where $c$ is carbon intensity per unit of passenger and freight turnover in $\mathrm{g} / \mathrm{t} \cdot \mathrm{km}$ or $\mathrm{g} / \mathrm{p} \cdot \mathrm{km} ; m_{f}$ is fuel consumption of vehicle $(\mathrm{L} / 100 \mathrm{~km}) ; \rho$ is fuel density: $0.85 \mathrm{~kg} / \mathrm{L}$ for diesel and $0.75 \mathrm{~kg} / \mathrm{L}$ for gasoline; $Q_{l}$ is average low calorific value of fuel $(\mathrm{kJ} / \mathrm{kg}) ; k$ is potential $\mathrm{CO}_{2}$ emission coefficient $(\mathrm{kg} / \mathrm{GJ})$, according to data released by the National Development and Reform Commission of the P.R.C., and the values are shown in Table 2. $W$ is the rated load or passenger capacity of a vehicle, and the unit is ton or person.

3.3.1. Data Acquisition and Analysis. The Ministry of Transport of China has started to manage the standards of fuel-based commercial buses and commercial trucks since 2008 and has established a database of highway transport vehicles that meet the standards [47]. Corresponding technical parameters of 2,000 related models from 2016 to 2018 have been obtained through inquiry and can basically 
TABLE 1: Indicators selection.

\begin{tabular}{|c|c|c|c|c|c|c|}
\hline \multirow{2}{*}{$\begin{array}{l}\text { Primary } \\
\text { indicators }\end{array}$} & \multirow[b]{2}{*}{ Secondary indicators } & \multicolumn{2}{|c|}{ First round of survey } & \multicolumn{3}{|c|}{ Second round of survey } \\
\hline & & $\begin{array}{l}\text { Full mark } \\
\text { frequency }\end{array}$ & $\begin{array}{l}\text { Grade } \\
\text { sum }\end{array}$ & $\begin{array}{l}\text { Full mark } \\
\text { frequency }\end{array}$ & $\begin{array}{c}\text { Grade } \\
\text { sum }\end{array}$ & $\begin{array}{c}\text { Coefficient of } \\
\text { variation }\end{array}$ \\
\hline \multirow{6}{*}{ Input indicator } & Number of employees & $71 \%$ & 54 & $75 \%$ & 115 & 0.11 \\
\hline & Number of vehicles & $83 \%$ & 60 & $80 \%$ & 120 & 0.24 \\
\hline & Asset investment & $60 \%$ & 31 & Delete & Delete & Delete \\
\hline & Fuel consumption & $74 \%$ & 55 & $78 \%$ & 99 & 0.12 \\
\hline & Total mileage driven & $50 \%$ & 35 & Delete & Delete & Delete \\
\hline & $\begin{array}{c}\text { Carbon trading } \\
\text { allowance }\end{array}$ & $95 \%$ & 71 & $98 \%$ & 135 & 0.14 \\
\hline \multirow{4}{*}{ Product indicator } & Output value & $90 \%$ & 68 & $90 \%$ & 128 & 0.09 \\
\hline & Transportation volume & $93 \%$ & 61 & $85 \%$ & 130 & 0.15 \\
\hline & Margin of transport & $50 \%$ & 31 & Delete & Delete & Delete \\
\hline & Value added & $30 \%$ & 20 & Delete & Delete & Delete \\
\hline
\end{tabular}

TABLE 2: Emission coefficient and low calorific value of fuel.

\begin{tabular}{lcc}
\hline Fuel type & Potential $\mathrm{CO}_{2}$ emission coefficient $(\mathrm{kg} / \mathrm{GJ})$ & Average low calorific value $(\mathrm{kJ} / \mathrm{kg})$ \\
\hline Diesel & 74.024 & 42705 \\
Gasoline & 69.363 & 43124 \\
\hline
\end{tabular}

cover the overall application situation of current operating vehicles in the industry. The carbon intensity of existing models is calculated by using formula (8). Figures 3 and 4, respectively, list the scattered points and distribution of carbon intensity of 1,679 truck models and 362 passenger vehicle models for statistical analysis of data.

As can be seen from Figure 3, the current application of commercial trucks in China presents many dense typical models, a wide coverage of rated load, and a large gap in carbon intensity. The rated load range of commercial trucks is about $3 \mathrm{t} \sim 40 \mathrm{t}$, and the main quality segment is concentrated between $8 \mathrm{t}$ and $20 \mathrm{t}$, which also shows that there are many truck models in China, and tractor models are concentrated. The carbon intensity per unit of freight turnover ranges from 40 to $190 \mathrm{~g} / \mathrm{t} \cdot \mathrm{km}$ and is most concentrated within the range of 50 to $100 \mathrm{~g} / \mathrm{t} \cdot \mathrm{km}$. A single payload may have different carbon intensities, and the probably reasons are as follows: firstly, based on the formula (8), the fuel consumption of vehicle has a great influence on carbon emission intensity. Meanwhile, the total mass of the vehicle has a great influence on the fuel consumption. The total mass of the vehicle is composed of vehicle weight and payload. The difference of vehicle weight leads to the difference of carbon emission intensity for the vehicles with the same payload. Therefore, for the vehicles with small payloads, vehicle weight takes a larger proportion in the total mass, resulting in a large difference in carbon emission. For the vehicles with large payloads, vehicle weight takes a small proportion in the total mass, resulting in a small difference in carbon emission. Secondly, the payloads between roughly 33000 and 40000 have a relatively similar range of carbon intensity. The reason is that this part of vehicles is mainly tractor trucks (different from the single trucks on the left in Figure 3). Vehicle weight takes a similar proportion in the total mass, resulting in a similar difference in carbon emission.

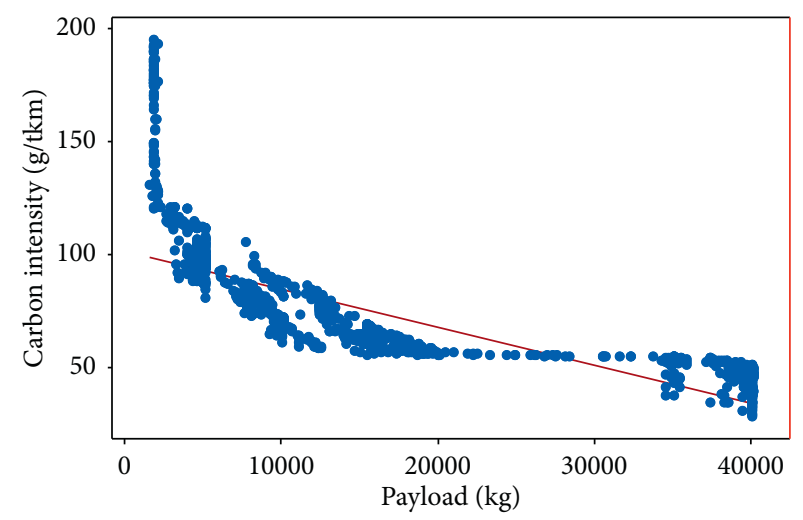

FIGURE 3: Scatter diagram of carbon intensity of operating trucks.

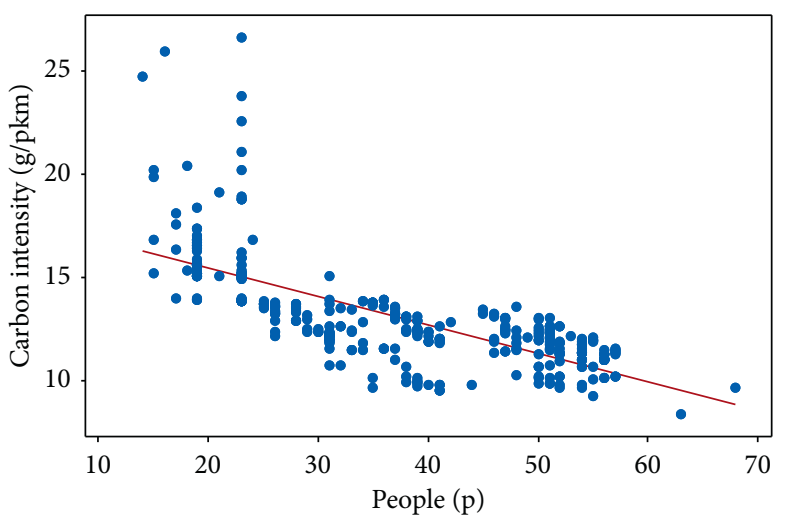

FIGURE 4: Scatter diagram of carbon intensity of commercial buses.

It can be seen from Figure 4 that the commercial buses are more concentrated than truck models, and the distribution of rated passenger capacity is even, and the gap in 
carbon intensity is large. The rated passenger capacity ranges from 15 to 55 people, and the number of models with each capacity range is relatively average. There are fewer models with a capacity of more than 55 people. This also indicates that China has a higher degree of standardization in commercial bus models. The carbon intensity per unit of passenger turnover ranges from 5 to $30 \mathrm{~g} / \mathrm{t} \cdot \mathrm{km}$ and is most concentrated within the range of 10 to $15 \mathrm{~g} / \mathrm{t} \cdot \mathrm{km}$. Based on the above analysis, it can be seen that in terms of carbon intensity per unit of turnover, the entire road transport industry has a large fluctuation range, with an obvious gap. This also proves that by introducing the baseline idea and scientifically delimitating the industry baseline value, the initial allocation of carbon emission quotas can have an effective incentive effect on the road transport industry.

3.3.2. Cumulative Distribution Function of Sample Data. Carbon emission intensity data is a set of continuous random variables. According to the central limit theorem, variables obey a normal distribution with a mathematical expectation of $\mu$ and a standard variance of $\sigma^{2}$. The probability density function is as follows:

$$
f(x ; \mu, \sigma)=\frac{1}{\sigma \sqrt{2 \pi}} \exp \left(-\frac{(x-\mu)^{2}}{2 \sigma^{2}}\right) .
$$

The probability distribution diagram of carbon emission intensity obtained by using formula (9) is shown in Figures 5 and 6.

As can be seen from Figures 5 and 6, the probability distribution of emission intensity is in good agreement with the normal distribution. We can confirm the cumulative distribution function of emission intensity by the following formula:

$$
F(x ; \mu, \sigma)=\frac{1}{\sigma \sqrt{2 \pi}} \int_{-\infty}^{x} \exp \left(-\frac{(x-\mu)^{2}}{2 \sigma^{2}}\right) \mathrm{d} x .
$$

By using regression analysis and curve fitting in the Minitab software, the cumulative probability density of the carbon intensity of vehicle models in each classification segment is calculated as shown in Figure 7.

It can be seen from Figure 7 that the cumulative probability density curve of the carbon intensity after the fitting of the commercial buses and trucks is close to the original value distribution, which proves that the fitted curve is in good compliance with the actual situation. By integrating the cumulative probability density distribution of the carbon intensity of various types of passenger vehicles and trucks in the road transport industry and selecting the value at $50 \%$ of the cumulative probability density as the industry baseline, the baseline value of industry carbon intensity calculated is shown in Table 3.

The baseline of vehicle carbon emission intensity is based on the vehicle model data rather than individual vehicle data. Although the data of 2000 models are selected, they can basically cover all models of operating vehicles in the current industry. Meanwhile, the fuel consumption data of each model is obtained through the full-load test specified in the

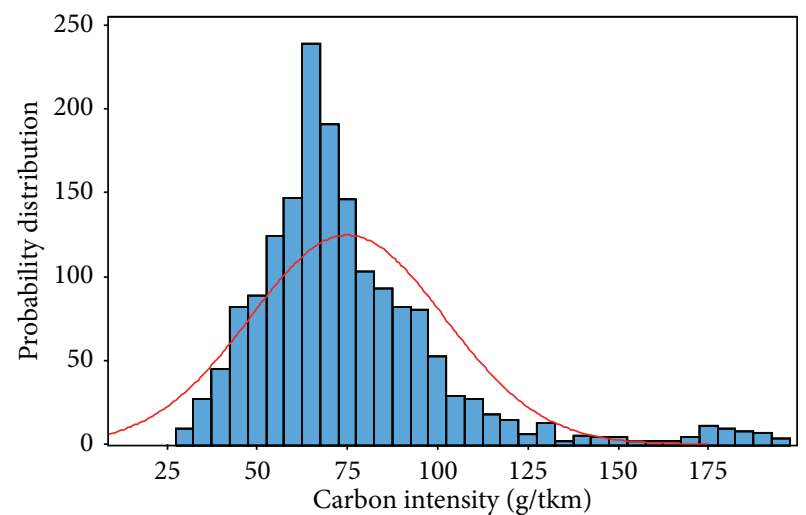

FIGURE 5: Probability distribution of emission intensity of operating trucks.

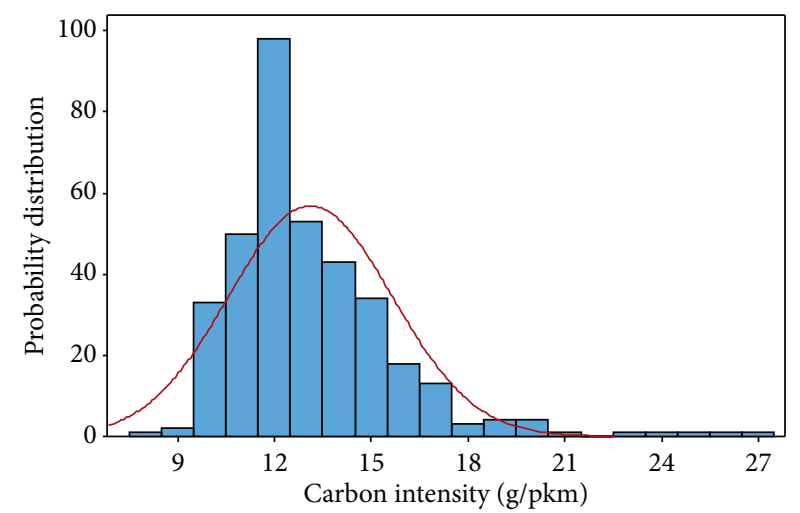

Figure 6: Probability distribution of emission intensity of commercial buses.

standard, which can effectively represent the emission intensity level of the vehicle. Therefore, the matching between the baseline value and the reality is guaranteed.

The purpose of vehicle carbon emission intensity baseline is to encourage the industry to reduce intensity as much as possible. Increasing vehicle payload is an important measure to reduce the intensity. Therefore, the baseline is determined based on the full load of the vehicle.

\section{Results and Discussion}

4.1. Data Collection. As the China Energy Statistical Yearbook 2019 has not yet been published, in order to ensure the consistency of data and time in the two yearbooks, this paper uses relevant data from the China Statistical Yearbook 2018 [48] and the China Energy Statistical Yearbook 2018 [48]. Specifically, data for Tibet are not complete and therefore not included for the time being. China Statistical Yearbook and China Energy Statistical Yearbook are published by the National Bureau of Statistics, PRC, every year, which contain relevant statistical data of all provinces in China. They are the most authoritative and comprehensive statistical yearbooks in China. The data are collected by the statistical departments of the provinces in accordance with the requirements of the statistical investigation system of China. 


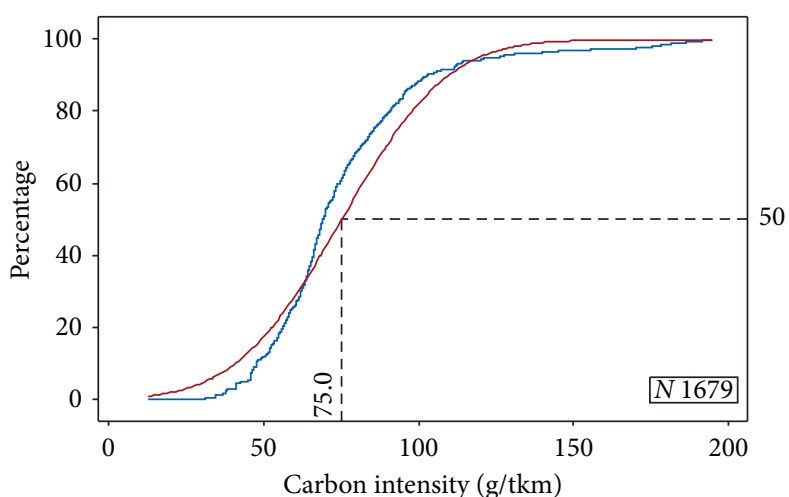

(a)

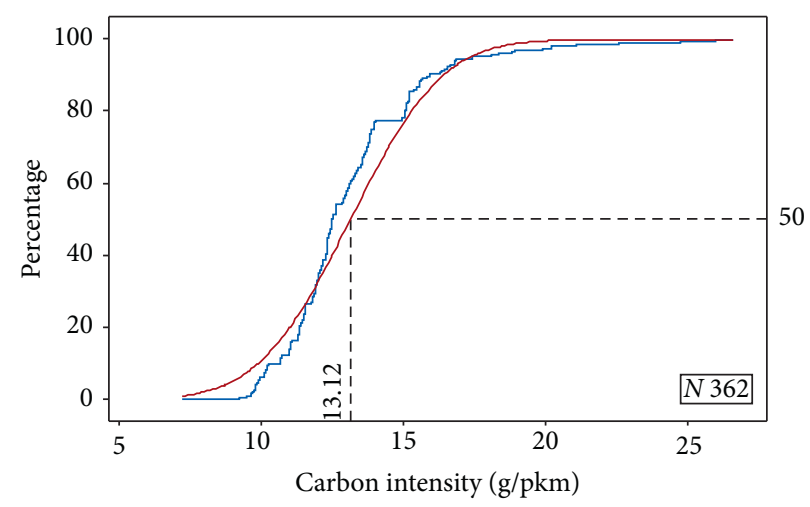

(b)

FIgURE 7: Cumulative probability distribution of carbon intensity of various types of passenger vehicles and trucks in the road transport industry. (a) Cumulative probability distribution of carbon intensity of commercial trucks. (b) Cumulative probability distribution of carbon intensity of commercial buses.

Provincial data are reported to the National Bureau of Statistics, PRC, level by level. The methods of data acquisition include general survey and sampling survey. Data from the sample survey also are extrapolated to the entire industry. To sum up, the data from statistical yearbooks can give a comprehensive account of economic and social development and energy consumption of China. Specific data are shown in Table 4. Data in columns 2-8 of the table are directly inquired from related statistical yearbooks.

Data in the rightmost column are obtained through calculation. The calculation method is as follows:

$$
f_{q 0}=c_{p} \cdot \varepsilon_{p}+c_{f} \cdot \varepsilon_{f},
$$

where $f_{q 0}$ is the initial quota allocation value based on the baseline in 10,000 tons; $c_{p}$ is the baseline value of carbon intensity of commercial buses: $13.12 \mathrm{~g} / \mathrm{p} \cdot \mathrm{km} ; c_{f}$ is the baseline value of carbon intensity of commercial trucks: $75.04 \mathrm{~g} / \mathrm{t} \cdot \mathrm{km} ; \varepsilon_{p}$ is passenger turnover in 100 million p.km; and $\varepsilon_{f}$ is freight turnover in 100 million t.km.

4.2. Carbon Emission Quotas in the Road Transportation Based on the BL-DEA Model. By using the established BLDEA model, the carbon emission quotas are shown in Table 5. Shandong and Guangdong have, respectively, obtained 39.50 million tons and 38.38 million tons of carbon emission quotas, ranking top two. Both provinces are regions with developed highway transport in China. They are among the best in the country in terms of vehicle ownership, development of the transport industry, and highway mileage. Guangdong's current highway mileage is the longest in the country. Henan, Anhui, Hunan, and Hebei have all obtained more than 30 million tons of quotas. These four provinces are also the provinces with large highway transport traffic in China. They are among the best in terms of vehicle ownership, number of practitioners, and fuel consumption. Shanghai and Beijing are two regions in the country allocated with least carbon emission right quotas. The first is that
TABLE 3: Baseline value of carbon intensity in the road transportation industry.

\begin{tabular}{lc}
\hline Vehicle type & Baseline value of carbon intensity \\
\hline Commercial trucks & $75.04 \mathrm{~g} / \mathrm{t} \cdot \mathrm{km}$ \\
Commercial buses & $13.12 \mathrm{~g} / \mathrm{p} \cdot \mathrm{km}$ \\
\hline
\end{tabular}

compared with other provinces, the scale of highway transport in these two large cities is still small. The second is that except for highway transport, railways, aviation, and other means of transport in Beijing and Shanghai are relatively developed, which have also reduced the volume of highway transport to a certain extent. In general, through macro analysis, the initial quotas allocation value calculated by using the BL-DEA model can better match the economic development level, the development status of the highway transport industry, and the scale of the highway transport industry in various regions. It is a basic and reasonable allocation method.

4.3. Carbon Reduction Potential Analysis of Provinces. Carbon emission intensity was taken as an important benchmark index in the BL-DEA model. Compared with the actual carbon emissions of 30 provinces, carbon emission quotas by BL-DEA can reflect carbon reduction potential. A comparison is shown in Figure 8.

As can be seen from Figure 8, in terms of carbon intensity, 53 percent of provinces have smaller quotas than their actual emissions and 47 percent of provinces have higher quotas than their actual emissions. Shanghai, Guangdong, and Xinjiang have the greatest carbon reduction potential. The carbon emission intensity of these three provinces is at a relatively high level. By improving the carrying capacity of transportation, applying carbon-reducing technologies, and optimizing transportation organization, carbon emission would be significantly reduced. Henan, Hunan, and Anhui have the largest increase in emission quotas. The carbon 
TABLE 4: Summary of various types of data in the road transport industry.

\begin{tabular}{|c|c|c|c|c|c|c|c|c|c|}
\hline $\begin{array}{l}\text { Province/ } \\
\text { city }\end{array}$ & $\begin{array}{l}\text { Output } \\
\text { value } \\
\text { (RMB100 } \\
\text { million) }\end{array}$ & $\begin{array}{c}\text { Traffic } \\
\text { volume } \\
(10,000 \\
\text { tons/ } \\
10,000 \\
\text { people })\end{array}$ & $\begin{array}{c}\text { Number of } \\
\text { practitioners } \\
(10,000 \\
\text { people })\end{array}$ & $\begin{array}{c}\text { Number } \\
\text { of } \\
\text { vehicles } \\
(10,000)\end{array}$ & $\begin{array}{c}\text { Fuel } \\
\text { consumption } \\
(10,000 \text { tons })\end{array}$ & $\begin{array}{c}\text { Passenger } \\
\text { turnover } \\
(100 \text { million } \\
\mathrm{p} \cdot \mathrm{km})\end{array}$ & $\begin{array}{c}\text { Freight } \\
\text { turnover } \\
(100 \\
\text { million } \\
\text { t.km) }\end{array}$ & $\begin{array}{c}\text { Actual } \\
\text { carbon } \\
\text { emissions } \\
(10,000 \\
\text { tons })\end{array}$ & $\begin{array}{c}\text { Quotas } \\
\text { allocation } \\
\text { based on } \\
\text { baseline } \\
(10,000 \\
\text { tons) }\end{array}$ \\
\hline Beijing & 1208.40 & 64855 & 27.98 & 24.39 & 172.69 & 99.87 & 167.41 & 545.91 & 139 \\
\hline Tianjin & 780.40 & 46970 & 6.16 & 18.83 & 370.35 & 76.40 & 404.10 & 1170.75 & 313 \\
\hline Hebei & 2497.88 & 261467 & 12.1 & 138.22 & 843.59 & 227.61 & 8550.15 & 2666.75 & 6442 \\
\hline Shanxi & 1052.14 & 141933 & 7.67 & 60.98 & 536.11 & 159.64 & 1907.75 & 1694.75 & 1452 \\
\hline $\begin{array}{l}\text { Inner } \\
\text { Mongolia }\end{array}$ & 1050.02 & 167841 & 6.58 & 30.95 & 426.62 & 122.43 & 2985.63 & 1348.63 & 2255 \\
\hline Liaoning & 1310.02 & 246092 & 12.25 & 77.57 & 1008.72 & 291.46 & 3152.29 & 3188.76 & 2402 \\
\hline Jilin & 603.12 & 69892 & 4.91 & 35.19 & 343.73 & 153.77 & 1189.23 & 1086.6 & 912 \\
\hline Heilongjiang & 801.33 & 63682 & 6.60 & 50.11 & 330.34 & 154.13 & 810.66 & 1044.27 & 628 \\
\hline Shanghai & 1344.54 & 42746 & 18.20 & 25.92 & 562.20 & 105.82 & 299.29 & 1777.22 & 238 \\
\hline Jiangsu & 3097.67 & 236276 & 24.67 & 90.63 & 821.31 & 716.64 & 2544.35 & 2596.32 & 2002 \\
\hline Zhejiang & 1938.17 & 238546 & 17.31 & 38.15 & 881.91 & 402.80 & 1964.10 & 2787.89 & 1526 \\
\hline Anhui & 875.38 & 334587 & 13.34 & 71.97 & 622.69 & 376.89 & 5451.62 & 1968.44 & 4138 \\
\hline Fujian & 1889.69 & 130657 & 9.67 & 27.14 & 429.53 & 212.04 & 1289.52 & 1357.83 & 995 \\
\hline Jiangxi & 866.30 & 206948 & 9.31 & 37.90 & 546.71 & 260.97 & 3759.94 & 1728.26 & 2854 \\
\hline Shandong & 3268.01 & 362851 & 22.49 & 115.96 & 1368.78 & 493.57 & 6859.68 & 4326.98 & 5210 \\
\hline Henan & 2162.85 & 328890 & 20.16 & 106.02 & 808.01 & 711.19 & 5893.92 & 2554.28 & 4514 \\
\hline Hubei & 1420.01 & 244135 & 15.72 & 38.06 & 865.85 & 453.44 & 2955.53 & 2737.12 & 2276 \\
\hline Hunan & 1496.01 & 295396 & 9.76 & 34.53 & 712.97 & 479.93 & 3114.85 & 2253.84 & 2399 \\
\hline Guangdong & 3580.94 & 409992 & 39.79 & 67.23 & 1676.09 & 1120.71 & 3890.32 & 5298.45 & 3065 \\
\hline Guangxi & 955.70 & 189523 & 6.75 & 38.99 & 538.43 & 351.10 & 2683.05 & 1702.08 & 2058 \\
\hline Hainan & 248.94 & 21687 & 2.40 & 6.01 & 108.26 & 74.38 & 84.55 & 342.23 & 73 \\
\hline Chongqing & 939.46 & 159214 & 13.40 & 29.74 & 514.22 & 260.43 & 1152.75 & 1625.55 & 899 \\
\hline Sichuan & 1595.80 & 254786 & 17.36 & 62.07 & 800.93 & 466.14 & 1814.95 & 2531.9 & 1422 \\
\hline Guizhou & 1070.22 & 179407 & 5.60 & 19.62 & 490.80 & 469.08 & 1146.51 & 1551.51 & 921 \\
\hline Yunnan & 366.59 & 169963 & 7.52 & 53.07 & 601.52 & 269.63 & 1489.23 & 1901.52 & 1152 \\
\hline Shaanxi & 832.62 & 191092 & 11.10 & 43.80 & 409.63 & 286.98 & 2301.37 & 1294.92 & 1764 \\
\hline Gansu & 293.50 & 100905 & 4.489 & 30.63 & 307.01 & 233.31 & 1118.97 & 970.52 & 870 \\
\hline Qinghai & 103.69 & 20777 & 1.55 & 8.21 & 128.92 & 50.77 & 275.74 & 407.54 & 213 \\
\hline Ningxia & 199.31 & 37099 & 1.23 & 10.06 & 124.03 & 47.46 & 398.19 & 392.08 & 305 \\
\hline Xinjiang & 668.15 & 102423 & 7.72 & 37.11 & 651.13 & 123.15 & 1476.70 & 2058.35 & 1124 \\
\hline
\end{tabular}

emission intensity of these three provinces is at a relatively low level. The most benefit would be obtained when carbon trading market opens.

4.4. Comparison and Discussion of Different Quota Allocation Methods. In order to compare the promotional effect on the development of the industry among the BL-DEA model and the most widely used historical responsibility law and baseline method methods, this paper carries out discussions from three aspects, respectively: efficiency, equity, and incentives. The efficiency of the allocation of initial allowances for carbon emission represents its role in the production and operation efficiency and the healthy development of the entire highway transport industry. The equity represents the difference between the emission quotas of the provinces and the average value of quotas among provinces. Smaller difference indicates that quotas are distributed more evenly among provinces, which can conducive to promotional effect in the industry. That means more equity. The incentive represents whether provinces with lower carbon intensity have certain quota incentives and provinces with higher carbon intensity have certain quotas penalties to promote the enthusiasm of the entire industry for energy conservation and carbon reduction.

In terms of efficiency comparison, the traditional CCR model proposed by Charnes et al. [49] was used. The quotas allocated by "baseline" method have been listed in Table 4. Under the historical responsibility method, quotas are allocated by the percentage of existing carbon emission data; the quotas are shown in Table 6.

It can be seen from Table 7 that under the "historical responsibility" method, Guangdong and Shandong have, respectively, obtained 50.8 million tons and 41.48 million tons of carbon emission right quotas, still ranking top two. The difference is that Guangdong becomes the province with the most allowance. The reason is that highway transport industry of Guangdong has the largest total carbon emissions, so it has been given the most initial allowance. Hainan has become the province with the least allowance in the country. Because Hainan is located on an island and the highway transport within the province cannot go out of the 
TABLE 5: Carbon emission quotas by the BL-DEA model.

\begin{tabular}{|c|c|}
\hline Province/city & Value (10,000 tons) \\
\hline Beijing & 139 \\
\hline Tianjin & 409 \\
\hline Hebei & 3132 \\
\hline Shanxi & 1501 \\
\hline Inner Mongolia & 1920 \\
\hline Liaoning & 2402 \\
\hline Jilin & 681 \\
\hline Heilongjiang & 628 \\
\hline Shanghai & 24 \\
\hline Jiangsu & 2620 \\
\hline Zhejiang & 2442 \\
\hline Anhui & 3514 \\
\hline Fujian & 1668 \\
\hline Jiangxi & 2155 \\
\hline Shandong & 3950 \\
\hline Henan & 3563 \\
\hline Hubei & 2385 \\
\hline Hunan & 3337 \\
\hline Guangdong & 3838 \\
\hline Guangxi & 2072 \\
\hline Hainan & 202 \\
\hline Chongqing & 1481 \\
\hline Sichuan & 2561 \\
\hline Guizhou & 2062 \\
\hline Yunnan & 1553 \\
\hline Shaanxi & 1973 \\
\hline Gansu & 980 \\
\hline Qinghai & 155 \\
\hline Ningxia & 402 \\
\hline Xinjiang & 810 \\
\hline
\end{tabular}

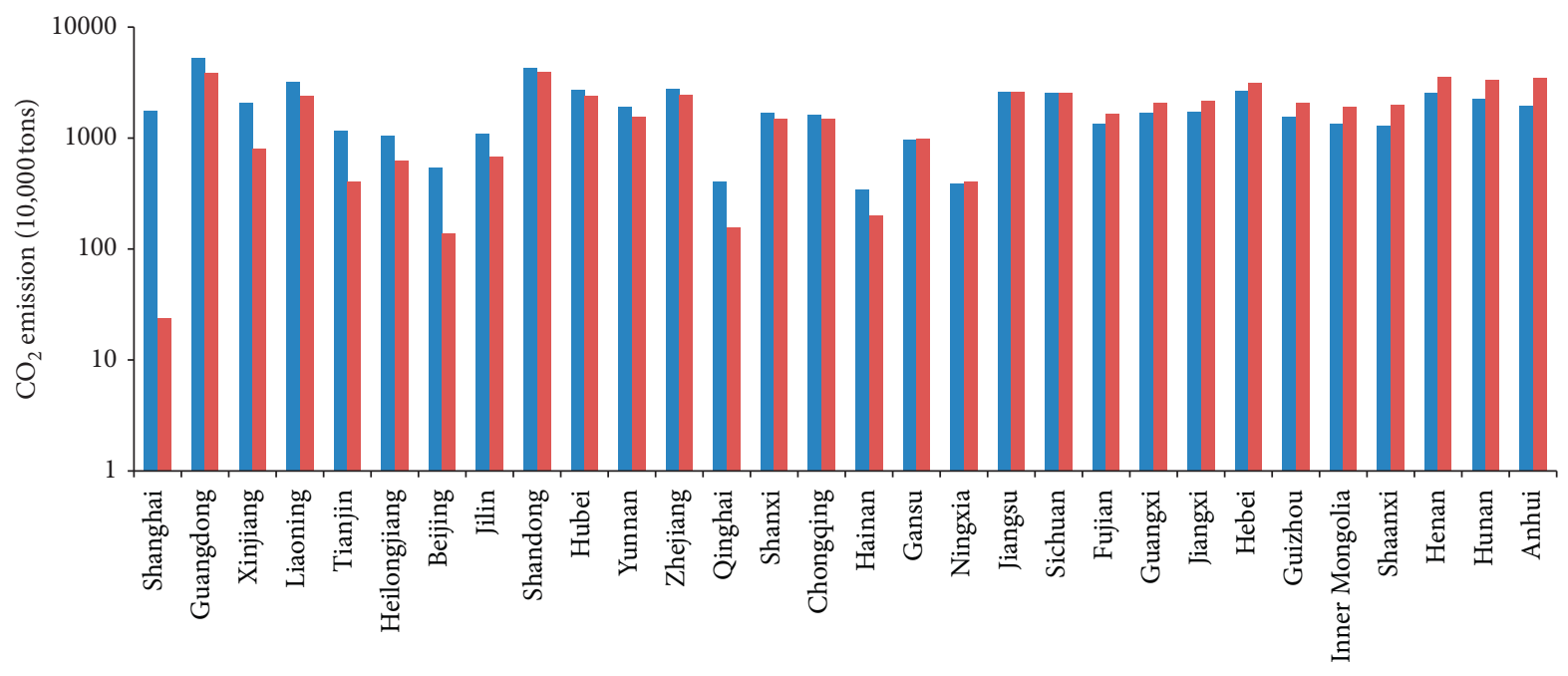

- Actual carbon emissions

- Emission quotas by BL-DEA model

FIGURE 8: Comparison of the actual carbon emission and emission quotas by BL-DEA model. 
TABLE 6: Allocation of quotas based on the "historical responsibility" method.

\begin{tabular}{lc}
\hline Province/city & Value $(10,000$ tons $)$ \\
\hline Beijing & 523 \\
Tianjin & 1122 \\
Hebei & 2557 \\
Shanxi & 1625 \\
Inner Mongolia & 1293 \\
Liaoning & 3057 \\
Jilin & 1042 \\
Heilongjiang & 1001 \\
Shanghai & 1704 \\
Jiangsu & 2489 \\
Zhejiang & 2673 \\
Anhui & 1887 \\
Fujian & 1302 \\
Jiangxi & 1657 \\
Shandong & 4148 \\
Henan & 2449 \\
Hubei & 2624 \\
Hunan & 2161 \\
Guangdong & 5080 \\
Guangxi & 1632 \\
Hainan & 328 \\
Chongqing & 1558 \\
Sichuan & 2427 \\
Guizhou & 1487 \\
Yunnan & 1823 \\
Shaanxi & 1241 \\
Qinghai & 930 \\
Ningxia & 391 \\
Xinjiang & 376 \\
\hline & 1973 \\
\hline
\end{tabular}

island, so its industry scale is small and it has become the province with the lowest carbon emissions. In addition, allowances in Ningxia and Qinghai do not exceed 4 million tons, mainly because the two provinces are relatively underdeveloped, with fewer people and freight flows, and the scale of highway transport is not large, resulting in small mileage carbon emission data.

The efficiency value based on the CCR method which was recorded as CCR-DEA efficiency is shown in Table 7. Further, changes in the efficiency values of the three allowance allocation methods are shown in Figure 9.

As can be seen from Table 7 and Figure 9, under the distribution model of the historical responsibility method, the CCR-DEA efficiency of 6 provinces including Beijing, Hebei, Anhui, Fujian, Hunan, and Guizhou reaches 1, and the number of such provinces accounts for $20 \%$ of all. The efficiency in Qinghai and Xinjiang is relatively poor at only 0.43 and 0.45 . The efficiency of the other 22 provinces exceeds 0.6. The average efficiency of 30 provinces is 0.81 . Under the distribution model of the baseline method, the CCR-DEA efficiency of 8 provinces including Beijing, Hebei, Shanghai, Anhui, Fujian, Hunan, Hainan, Guizhou, and Shaanxi reaches 1 , and the number of such provinces accounts for $27 \%$ of all. The efficiency in Qinghai and Xinjiang is still poor at 0.49 and 0.47 , respectively. The efficiency of the other 22 provinces exceeds 0.6 , and the efficiency of most provinces has shown an increasing trend. The average efficiency of 30 provinces has increased to 0.86 . This also proves that in the current two allocation models in common use, the allocation efficiency under the baseline method is relatively higher and can better promote the development of the industry. Under the BL-DEA allocation model, through the adjustment of the provinces under a fixed overall allowance, the efficiency of all provinces has reached 1. This shows that the BL-DEA allocation model is more scientific, as compared with the existing two allocation methods, taking into account the benign development of the industry and the efficiency of production and operation.

In terms of allocation equity, the initial allowances allocated to each province under the three different allocation models are also somewhat different. A comparison of the equity in allowance for carbon emission under three allocation methods is shown in Figure 10.

It can be seen from Figure 10 that quotas of most provinces under the BL-DEA model are between the others. In order to quantitatively compare the equity of the three allocation methods, this paper uses variance to measure the difference between the emission quotas of the provinces and the average value of quotas among provinces. The calculation method of the variance is as follows:

$$
\sigma^{2}=\frac{\sum(X-\mu)^{2}}{N}
$$

where $\sigma^{2}$ is the variance of emission quotas under different allocation methods; $X$ is the values of emission quotas for each province under different allocation methods; $\mu$ is the average value of quotas among provinces; $N$ is the number of provinces.

After calculation, the variances under the three methods, namely, "historical responsibility," "baseline," and "BL-DEA model," are 1087178, 2386464, and 1376641, respectively. Considering that the incentive effect will inevitably result in loss of equity, the variance under the "baseline" distribution model is the largest. The allocation variance under the BLDEA model has been significantly reduced compared to the "baseline" method and has been slightly increased compared to the "historical responsibility" method. This indicates that the model can better achieve equity while ensuring efficiency and incentives and is more conducive to the implementation of the carbon trading system in the entire highway transport industry.

It can effectively increase the enthusiasm of enterprises participating carbon trading in energy conservation and carbon reduction by reflecting the incentive effect in the allocation of initial allowances for carbon emission to various provinces. This will greatly promote the achievement of the national carbon emission reduction goal. Therefore, this is also an important factor in evaluating allocation models. A comparison of carbon emission incentives under the three allocation models is shown in Figure 11.

It can be seen from Figure 11 that the allocation trends of three allowance allocation methods of initial allowances for all provinces are roughly the same, but there are still some differences among different provinces. Compared with the 
TABLE 7: Efficiency of allocation methods.

\begin{tabular}{|c|c|c|c|}
\hline Province/city & Historical responsibility method & Baseline method & BL-DEA \\
\hline Beijing & 1.00 & 1.00 & 1.00 \\
\hline Tianjin & 0.65 & 0.98 & 1.00 \\
\hline Hebei & 1.00 & 1.00 & 1.00 \\
\hline Shanxi & 0.74 & 0.74 & 1.00 \\
\hline Inner Mongolia & 0.99 & 0.99 & 1.00 \\
\hline Liaoning & 0.64 & 0.64 & 1.00 \\
\hline Jilin & 0.62 & 0.63 & 1.00 \\
\hline Heilongjiang & 0.62 & 0.68 & 1.00 \\
\hline Shanghai & 0.75 & 1.00 & 1.00 \\
\hline Jiangsu & 0.88 & 0.88 & 1.00 \\
\hline Zhejiang & 0.84 & 0.87 & 1.00 \\
\hline Anhui & 1.00 & 1.00 & 1.00 \\
\hline Fujian & 1.00 & 1.00 & 1.00 \\
\hline Jiangxi & 0.84 & 0.84 & 1.00 \\
\hline Shandong & 0.77 & 0.77 & 1.00 \\
\hline Henan & 0.94 & 0.94 & 1.00 \\
\hline Hubei & 0.74 & 0.74 & 1.00 \\
\hline Hunan & 1.00 & 1.00 & 1.00 \\
\hline Guangdong & 0.86 & 0.86 & 1.00 \\
\hline Guangxi & 0.90 & 0.90 & 1.00 \\
\hline Hainan & 0.62 & 1.00 & 1.00 \\
\hline Chongqing & 0.75 & 0.85 & 1.00 \\
\hline Sichuan & 0.75 & 0.88 & 1.00 \\
\hline Guizhou & 1.00 & 1.00 & 1.00 \\
\hline Yunnan & 0.73 & 0.77 & 1.00 \\
\hline Shaanxi & 0.95 & 1.00 & 1.00 \\
\hline Gansu & 0.77 & 0.82 & 1.00 \\
\hline Qinghai & 0.43 & 0.49 & 1.00 \\
\hline Ningxia & 0.94 & 0.94 & 1.00 \\
\hline Xinjiang & 0.45 & 0.47 & 1.00 \\
\hline Average efficiency & 0.81 & 0.86 & 1.00 \\
\hline
\end{tabular}

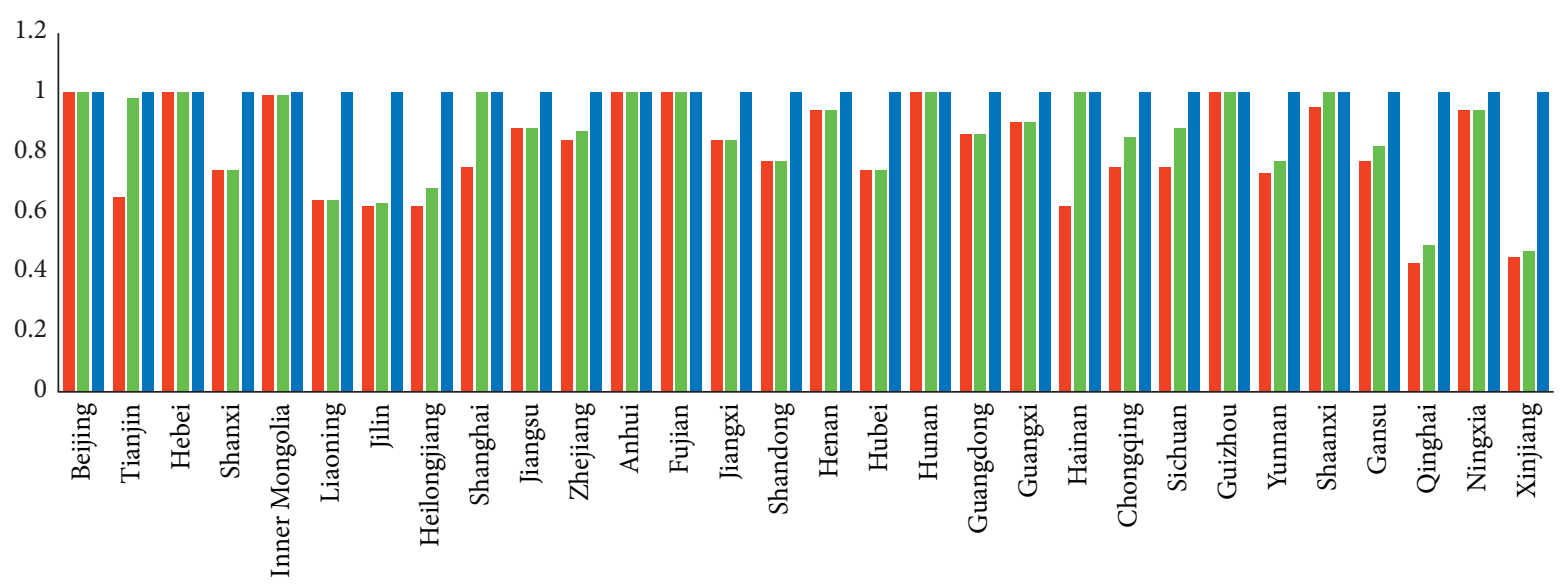

- Historical responsibility

- Baseline

- BL-DEA

Figure 9: Comparison of the efficiency of three allocation methods in 30 provincial regions.

"historical responsibility method," in terms of incentives, under the BL-DEA allocation model, Shandong and Guangdong still occupy the top two places in allowance allocation, but Guangdong has dropped from the first place under the "historical responsibility method" to the second place. This is mainly attributable to the relatively high carbon intensity per unit of traffic volume in Guangdong's highway transport industry. The allowances under the BL-DEA model are reduced as compared with the initial allowances, which clearly reflect the incentive effect of the BL-DEA 


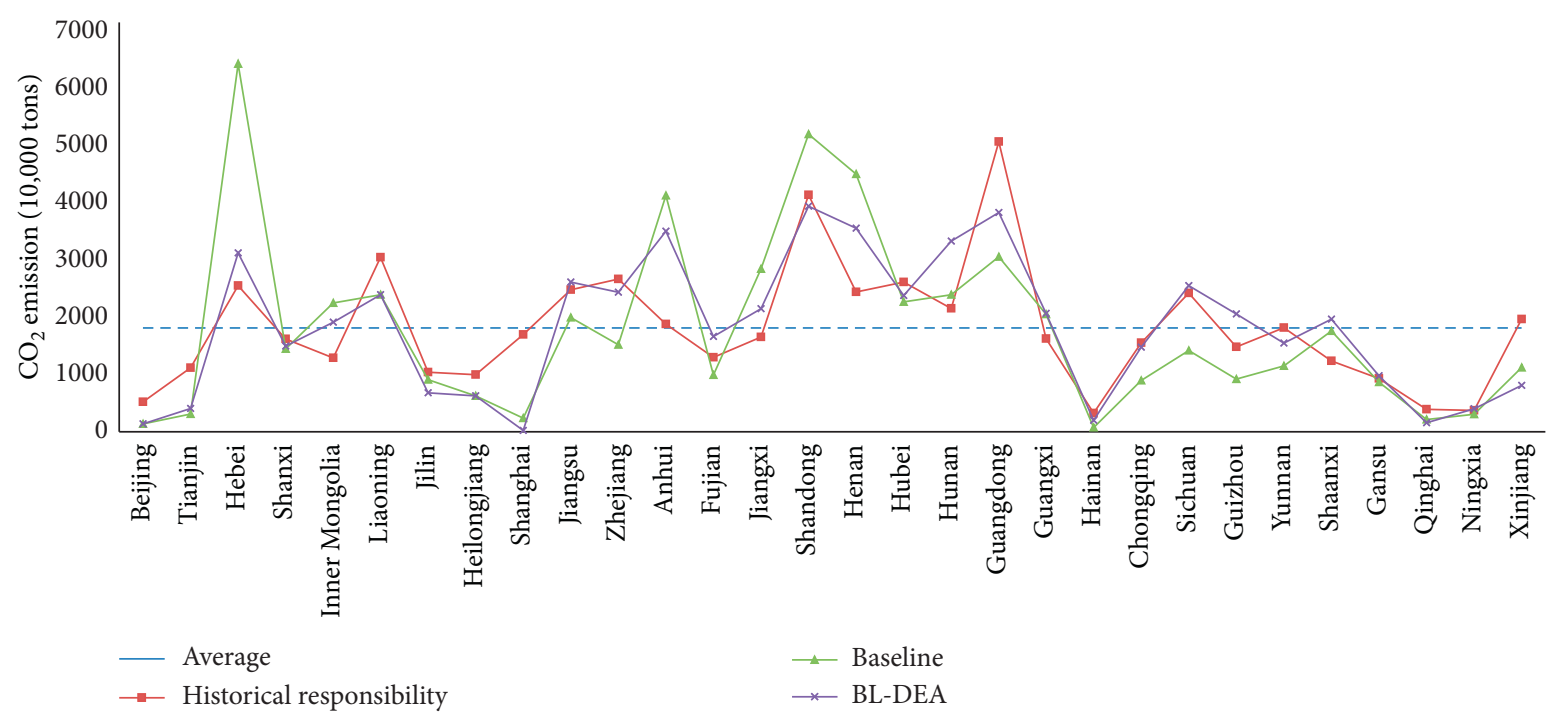

FIgURE 10: A comparison of the equity in allowances for carbon emission under three allocation methods.

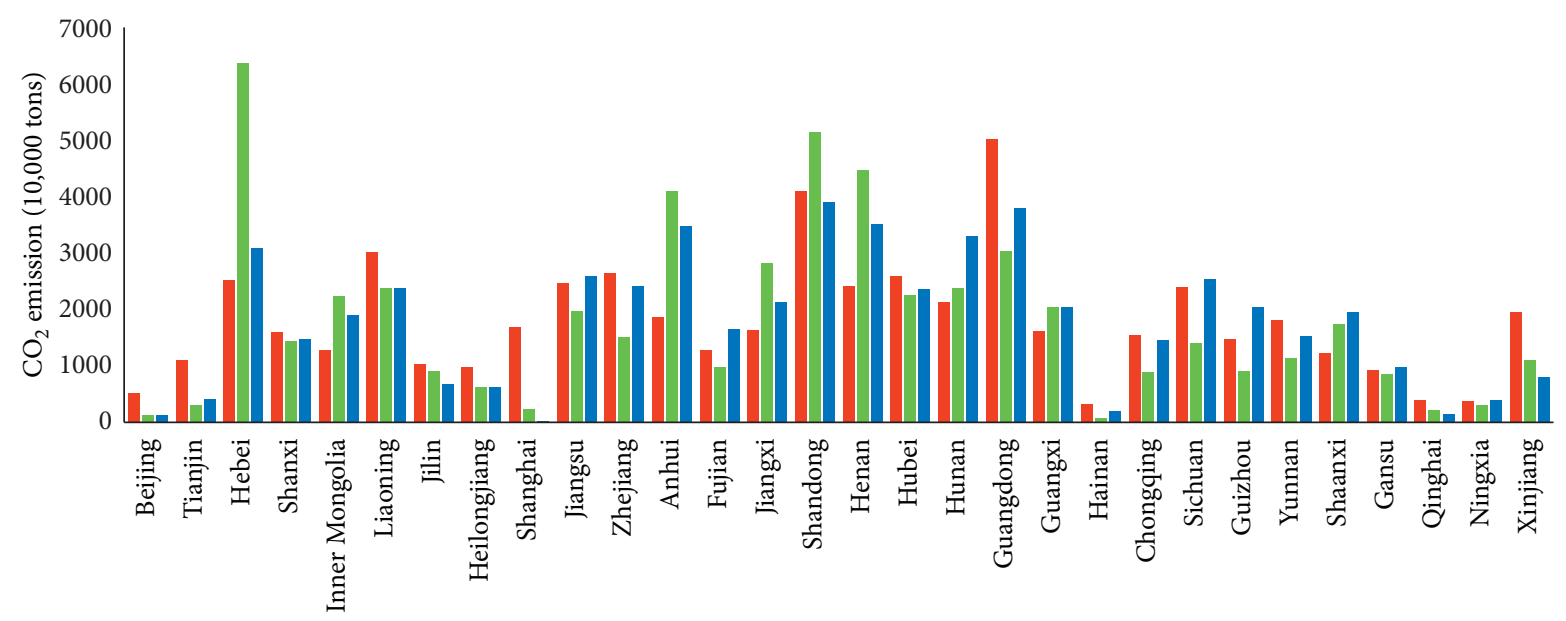

- Historical responsibility

- Baseline

- BL-DEA

Figure 11: A comparison of carbon emission incentives under the three allocation models.

model. Incentive effect is also reflected in Heilongjiang, Jilin, and Liaoning. The three provinces are located in Northeast China, and the climate there is cold. Due to the longer use of air conditioning during driving, the fuel consumption and carbon emissions of the vehicles are higher than the industry average carbon intensity values. Therefore, the allowances under the BL-DEA model are reduced accordingly as compared with the initial allowances. In Beijing and Shanghai, the unit carbon intensity is higher than the industry average, and the initial allowances under the BL-DEA model decline, due to more congested urban conditions, lower vehicle loading rates, and most light freights with higher added value. The initial allowances allocated under the BL-DEA model to Henan, Anhui, Hunan, and Hebei are higher than those allocated under the "historical responsibility method" because these four provinces have a large proportion of freight and obtain a higher freight turnover with a lower number of vehicles and low fuel consumption. That is, the actual loading rate in the vehicle application process is relatively high, and the carbon intensity per unit of turnover is relatively low, so such model gives incentives of certain allowances. In addition, the BLDEA model introduces output value indicators that characterize the economic development level in the regions and can encourage economically developed regions to simulate the enthusiasm of less developed regions in energy conservation and carbon reduction through the purchase of allowances. This has led to the decrease in the allowances allocated under the BL-DEA model to Guangdong, Shanghai, Beijing, Zhejiang, and other economically 
developed regions and led to general and certain increase in the allowances allocated under the BL-DEA to central and western regions such as Henan, Hunan, Guizhou, and Shanxi.

Compared with the "baseline method," the quotas under the BL-DEA model to Hebei Province have decreased by 33.1 million tons. Hebei is located on the plains and is China's largest province for freight transport. Freight transport is mainly long-distance transport and drop and pull transport (a motor vehicle drops the loading device attached to the vehicle at the destination and then pulls other loaded devices back to the original place or a new location). Freight mileage is nearly three times that of Guangdong, and the actual load rate is relatively high. This has caused Hebei's carbon intensity per unit of freight turnover to be significantly lower than the industry average. Therefore, the "baseline method," which uses incentives as its main indicator, gives large allowances. However, under the BL-DEA model, in order to consider efficiency and equity as a whole, allowances allocated to Hebei have been greatly reduced. For allowances allocated to other provinces, the allowances allocated under the BL-DEA model fluctuate to some extent based on the allowances allocated under the "baseline method," but the fluctuation is not great. This proves that the allowances under the model significantly approximate those under the "'baseline method" and such model can effectively reflect the effect of incentives.

Based on the above analysis, it can be seen that BL-DEA, as a comprehensive initial allowance allocation model, has greater growth in allocation efficiency than the other two models, as compared with the current "historical responsibility method" and the "baseline method" that are most widely used, with the comprehensive allocation efficiency increasing by $19 \%$ and $14 \%$, respectively. In terms of allocation equity, compared with the "baseline method," it can better balance equity and has little difference from the "historical responsibility method." In terms of allocation incentive effect, compared with the "historical responsibility method," the incentive effect is obvious. Compared with the "baseline method," except for Hebei, the allocation incentive effect to other provinces has reached a relatively high level.

\section{Conclusion}

This paper establishes an improved initial allowance allocation model from the perspective of carbon emission intensity, which can be applied to the road transportation. Initial quotas are allocated to 30 provinces and regions in China by the use of the proposed model. The conclusion is as follows:

(1) The carbon emission intensity of commercial trucks and buses in China's road transport industry is $75.04 \mathrm{~g} / \mathrm{t} \cdot \mathrm{km}$ and $13.12 \mathrm{~g} / \mathrm{p} \cdot \mathrm{km}$, respectively.

(2) In terms of carbon emission reduction potential, 53 percent of provinces have smaller quotas than their actual emissions; 47 percent of provinces have higher quotas than their actual emissions; Shanghai,
Guangdong, and Xinjiang have the greatest carbon reduction potential; Henan, Hunan, and Anhui have the largest increases in emission quotas.

(3) In terms of allocation efficiency, the proportion of provinces with an allocation efficiency of 1 increases from $20 \%$ under the "history responsibility" method and $27 \%$ under the "baseline" method to $100 \%$. The comprehensive average allocation efficiency increases from 0.81 under the "historical responsibility" method and from 0.86 under the "baseline" method, to 1 , increasing by $19 \%$ and $14 \%$, respectively.

(4) The proposed model comprehensively considers the incentive effect brought by the high and low unit carbon intensity across provinces and local economic development level. In terms of allocation equity, the allocation variance under the BL-DEA model declines significantly as compared with that under the "baseline method" and increases slightly as compared with that under the "historical responsibility."

Due to the limitations of the study, there are still some areas in this paper that need improvement in future research. The first is that the data used in this paper are the current base year data. The current data are utilized to clarify the validity of the BL-DEA model in the allocation of initial allowances for carbon emission. In future work, the carbon emission forecast shall be carried out according to the economic development level in China and the transport development level in various regions, and then, an allowance allocation study shall be conducted for the target year based on the forecast. The second is that this study only focuses on traditional fuel vehicles rather than new energy vehicles, due to the fact that the current application of new energy vehicles in the road transport industry has not yet formed a scale. With the increasing new energy vehicles, in future research, efforts shall be made to explore the impact on the allocation of initial allowances for carbon emission after an enterprise uses new energy vehicles.

\section{Data Availability}

The input-output indicator data of road transportation used to support the findings are included within the article. The data of carbon emission intensity used to support the findings have been deposited in the Figshare repository (https://doi.org/10.6084/m9.figshare.12291248.v1). The database contains the carbon emission intensity of the unit turnover of passenger and cargo vehicles in China, which can be used to calculate the carbon emission intensity baseline of the road transportation.

\section{Conflicts of Interest}

The authors declare that there are no conflicts of interest regarding the publication of this paper. 


\section{Acknowledgments}

This work was supported in part by the National Key R\&D Program of China, grant number (2018YFB0105205-02) and (2017YFC0804803), and the Technology and Innovation Foundation of Research Institute of Highway Ministry of Transport, grant number (2018-A0017).

\section{References}

[1] L.-C. Liu, Q.-M. Liang, and Q. Wang, “Accounting for China's regional carbon emissions in 2002 and 2007: productionbased versus consumption-based principles," Journal of Cleaner Production, vol. 103, pp. 384-392, 2015.

[2] T. Wang and J. Watson, "Scenario analysis of China's emissions pathways in the 21st century for low carbon transition," Energy Policy, vol. 38, no. 7, pp. 3537-3546, 2010.

[3] F. Li, A. Emrouznejad, G.-l. Yang, and Y. Li, "Carbon emission abatement quota allocation in Chinese manufacturing industries: an integrated cooperative game data envelopment analysis approach," Journal of the Operational Research Society, vol. 71, no. 8, pp. 1259-1288, 2020.

[4] K. Wang, X. Zhang, Y.-M. Wei, and S. Yu, "Regional allocation of $\mathrm{CO} 2$ emissions allowance over provinces in China by 2020," Energy Policy, vol. 54, pp. 214-229, 2013.

[5] MOT of PRC, "The 2018 statistical bulletin on the development of the transport sector," 2018, http://xxgk.mot.gov.cn/ jigou/zhghs/201904/t20190412_3186720.html.

[6] A. D. Ellerman and B. K. Buchner, "Over-allocation or abatement? A preliminary analysis of the EU ETS based on the 2005-06 emissions data," Environmental and Resource Economics, vol. 41, no. 2, pp. 267-287, 2008.

[7] B. Anderson and C. Di Maria, "Abatement and allocation in the pilot phase of the EU ETS," Environmental and Resource Economics, vol. 48, no. 1, pp. 83-103, 2010.

[8] C. BoeHringer, H. Koschel, and U. Moslener, "Efficiency losses from overlapping regulation of EU carbon emissions," Journal of Regulatory Economics, vol. 33, no. 3, pp. 299-317, 2008.

[9] A. Frank Venmans, "literature-based multi-criteria evaluation of the EUETS," Renewable and Sustainable Energy Reviews, vol. 16, pp. 5493-5510, 2012.

[10] A. H. Westing, "Law of the air," Environment, vol. 31, no. 3, pp. 3-4, 1989.

[11] J. Jensen and T. N. Rasmussen, "Allocation of CO2 emissions permits: a general equilibrium analysis of policy instruments," Journal of Environmental Economics and Management, vol. 40, no. 2, pp. 111-136, 2000.

[12] M. Grubb, "The greenhouse effect: negotiating targets," International Affairs, vol. 66, no. 1, pp. 67-89, 1990.

[13] S. Kvemdokk, "Tradable CO2 emission permits: initial distribution as a justice problem," Environment Values, vol. 4, no. 2, pp. 129-148, 1995.

[14] W.-J. Yi, L.-L. Zou, J. Guo, K. Wang, and Y.-M. Wei, "How can China reach its $\mathrm{CO} 2$ intensity reduction targets by 2020 ? A regional allocation based on equity and development," Energy Policy, vol. 39, no. 5, pp. 2407-2415, 2011.

[15] S. Yu, X. Gao, C. Ma, and L. Zhai, "Study on the concept of per capita cumulative emissions and allocation options," $A d$ vances in Climate Change Research, vol. 2, no. 2, pp. 79-85, 2011.

[16] Gragelman, "Financing for climate change," Energy Economics, vol. 34, pp. 29-33, 2012.
[17] J. A. Filar and P. S. Gaertner, "A regional allocation of world CO2 emission reductions," Mathematics and Computers in Simulation, vol. 43, no. 3-6, pp. 269-275, 1997.

[18] J. Eyckmans and H. Tulkens, "Simulating coalitionally stable burden sharing agreements for the climate change problem," Resource and Energy Economics, vol. 25, no. 4, pp. 299-327, 2003.

[19] V. Laurent, M. Vielle, and A. Haurie, "A two-level computable equilibrium model to assess the strategic allocation of emission allowances within the European Union," Computers and Operations Research, vol. 33, no. 2, pp. 369-385, 2006.

[20] G. Phylipsen, J. Bode, K. Blok, H. Merkus, and B. Metz, “A Triptych sectoral approach to burden differentiation; GHG emissions in the European bubble," Energy Policy, vol. 26, no. 12, pp. 929-943, 1998.

[21] H. Groenenberg, D. Phylipsen, and K. Blok, "Differentiating commitments world wide: global differentiation of GHG emissions reductions based on the Triptych approach-a preliminary assessment," Energy Policy, vol. 29, no. 12, pp. 1007-1030, 2001.

[22] M. G. J. Den Elzen, M. Berk, P. Lucas, P. Criqui, and A. Kitous, "Multi-stage: a rule-based evolution of future commitments under the climate change convention," International Environmental Agreements: Politics, Law and Economics, vol. 6, no. 1, pp. 1-28, 2006.

[23] M. Den Elzen, N. Höhne, and S. Moltmann, “The Triptych approach revisited: a staged sectoral approach for climate mitigation," Energy Policy, vol. 36, no. 3, pp. 1107-1124, 2008.

[24] C. Böhringer and H. Welsch, "Contraction and Convergence of carbon emissions: an intertemporal multi-region CGE analysis," Journal of Policy Modeling, vol. 26, no. 1, pp. 21-39, 2004.

[25] T. Ekholm, S. Soimakallio, S. Moltmann, H. Niklas, S. Syri, and I. Savolainen, "Effort sharing in ambitious, global climate change mitigation scenarios," Energy Policy, vol. 38, no. 4, pp. 1797-1810, 2009.

[26] P. Baer, T. Athanasiou, S. Kartha et al., "The right to development in a climate constrained world: the Greenhouse Development Rights framework," Gastroenterology, vol. 191, no. 10, pp. 205-226, 2007.

[27] B.-J. Tang, Y.-J. Hu, and Y. Yang, "The initial allocation of carbon emission quotas in China based on the industry perspective," Emerging Markets Finance and Trade, vol. 8, pp. 1-18, 2019.

[28] R. Han, B.-Y. Yu, B.-J. Tang, H. Liao, and Y.-M. Wei, "Carbon emissions quotas in the Chinese road transport sector: a carbon trading perspective," Energy Policy, vol. 106, pp. 298-309, 2017.

[29] W. D. Cook and M. Kress, "Characterizing an equitable allocation of shared costs: a DEA approach," European Journal of Operational Research, vol. 119, no. 3, pp. 652-661, 1999.

[30] S. Lozano and G. Villa, "Centralized resource allocation using data envelopment analysis," Journal of Productivity Analysis, vol. 22, no. 1-2, pp. 143-161, 2004.

[31] S. Lozano, G. Villa, and R. Brannlund, "Centralized reallocation of emission permits using DEA," European Journal of Operational Research, vol. 193, no. 2, pp. 752-760, 2009.

[32] M. P. E. Lins, E. G. Gomes, J. C. C. B. Soares de Mello, and A. J. R. Soares de Mello, "Olympic ranking based on a zero sum gains DEA model," European Journal of Operational Research, vol. 148, no. 2, pp. 312-322, 2003.

[33] T. Lin and J. F. Ning, "Research on carbon emission allocation efficiency of EU countries based on ZSG-DEA model," Quantitative \& Technical Economics, vol. 3, pp. 36-50, 2011. 
[34] R.-Z. Pang, Z.-Q. Deng, and Y.-H. Chiu, "Pareto improvement through a reallocation of carbon emission quotas," Renewable and Sustainable Energy Reviews, vol. 50, pp. 419430, 2015.

[35] C. Feng, F. Chu, J. Ding, G. Bi, and L. Liang, "Carbon Emissions Abatement (CEA) allocation and compensation schemes based on DEA," Omega, vol. 53, pp. 78-89, 2015.

[36] Y. H. Chiu, J. C. Lin, C.-C. Hsu, and J. W. Lee, "Carbon emission allowances of efficiency analysis: application of super SBM ZSG-DEA model," Polish Journal of Environmental Studies, vol. 22, no. 3, pp. 653-666, 2013.

[37] Y. H. Chung, R. Färe, and S. Grosskopf, "Productivity and undesirable outputs: a directional distance function approach," Journal of Environmental Management, vol. 51, no. 3, pp. 229-240, 1997.

[38] P. Zhou, B. W. Ang, and D. Q. Zhou, "Measuring economywide energy efficiency performance: a parametric frontier approach," Applied Energy, vol. 90, no. 1, pp. 196-200, 2012.

[39] L. M. Seiford and J. Zhu, "Modeling undesirable factors in efficiency evaluation," European Journal of Operational Research, vol. 142, no. 1, pp. 16-20, 2002.

[40] S. Reinhard, C. A. Knox Lovell, and G. J. Thijssen, "Environmental efficiency with multiple environmentally detrimental variables; estimated with SFA and DEA," European Journal of Operational Research, vol. 121, no. 2, pp. 287-303, s2000.

[41] B. Zhang, J. Bi, Z. Fan, Z. Yuan, and J. Ge, "Eco-efficiency analysis of industrial system in China: a data envelopment analysis approach," Ecological Economics, vol. 68, no. 1-2, pp. 306-316, 2008.

[42] T. Sueyoshi, M. Goto, and T. Ueno, "Performance analysis of US coal-fired power plants by measuring three DEA efficiencies," Energy Policy, vol. 38, no. 4, pp. 1675-1688, 2010.

[43] T. Sueyoshi and M. Goto, "DEA approach for unified efficiency measurement: assessment of Japanese fossil fuel power generation," Energy Economics, vol. 33, no. 2, pp. 292-303, 2011.

[44] J. E. Beasley, "Allocating fixed costs and resources via data envelopment analysis," European Journal of Operational Research, vol. 147, no. 1, pp. 198-216, 2003.

[45] C. Okoli and S. D. Pawlowski, "The Delphi method as a research tool: an example, design considerations and applications," Information \& Management, vol. 42, no. 1, pp. 15-29, 2004.

[46] S. Keeney, F. Hasson, and H. McKenna, "Consulting the oracle: ten lessons from using the Delphi technique in nursing research," Journal of Advanced Nursing, vol. 53, no. 2, pp. 205-212, 2006.

[47] MOT of PRC, "Database of standard models of road transport vehicles," http://atestsc.mot.gov.cn/index.

[48] National Bureau of Statistics PRC, China Statistical Yearbook, China Statistical Publishing House, Beijing, China, 2018.

[49] A. Charnes, W. W. Cooper, and E. Rhodes, "Measuring the efficiency of decision making units," European Journal of Operational Research, vol. 2, no. 6, pp. 429-444, 1978. 